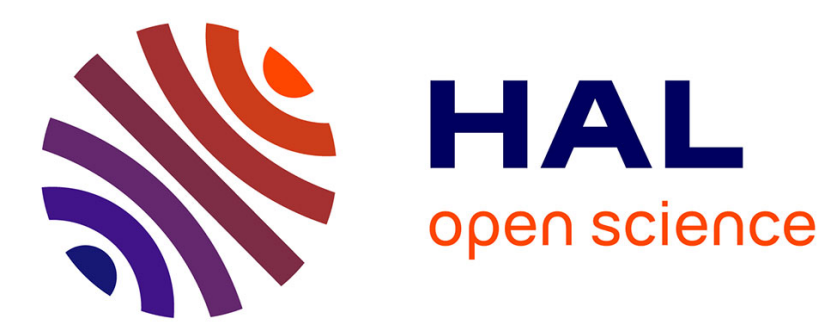

\title{
Comparing the integral characteristics of secondary droplet atomization under different situations
}

Nikita Shlegel, Pavel Strizhak, Dominique Tarlet, Jérôme Bellettre

\section{To cite this version:}

Nikita Shlegel, Pavel Strizhak, Dominique Tarlet, Jérôme Bellettre. Comparing the integral characteristics of secondary droplet atomization under different situations. International Communications in Heat and Mass Transfer, 2019, 108, pp.104329. 10.1016/j.icheatmasstransfer.2019.104329 . hal02372712

\section{HAL Id: hal-02372712 \\ https://hal.science/hal-02372712}

Submitted on 26 Feb 2021

HAL is a multi-disciplinary open access archive for the deposit and dissemination of scientific research documents, whether they are published or not. The documents may come from teaching and research institutions in France or abroad, or from public or private research centers.
L'archive ouverte pluridisciplinaire HAL, est destinée au dépôt et à la diffusion de documents scientifiques de niveau recherche, publiés ou non, émanant des établissements d'enseignement et de recherche français ou étrangers, des laboratoires publics ou privés. 
Comparing the integral characteristics of secondary droplet atomization under different situations Nikita Shlegel $^{1}$, Pavel Strizhak ${ }^{1 * *}$, Dominique Tarlet $^{2 *}$, Jérôme Bellettre ${ }^{2}$

${ }^{1}$ National Research Tomsk Polytechnic University, Heat Mass Transfer Simulation Laboratory, Russia, 30, Lenin Avenue, Tomsk, 634050, Russia.

${ }^{2}$ Laboratoire de Thermique et Énergie de Nantes (LTeN), CNRS UMR 6607, Université de Nantes, Rue Christian Pauc, BP 50609, 44306 Nantes cedex 3, France.

*E-mail: dominique.tarlet@univ-nantes.fr.

**E-mail: pavelspa@tpu.ru.Tel.:+7(3822)701-777, ex. 1910. Website: http://hmtslab.tpu.ru.

\begin{abstract}
In this paper, we describe the results of experimental research into secondary droplet atomization for several heterogeneous, water-oily liquid compositions including some highly heterogeneous emulsions and slurries. The group of schemes is studied, in addition to relevant experiments reported in the literature: droplets colliding with each other, with a heated or not heated walls, and with an air flow, as well as exposed to conductive or convective heating followed by micro-explosive breakup. After the analysis of experimental data, we calculate the size and number distributions of the liquid fragments generated using each of the approaches. We determine the duration of initial droplets' fragmentation as a function of the We numbers and the density of the supplied heat flux. The comparative analysis gave us optimal conditions for several aerosol generation techniques providing minimal fragment size with relatively low electric power consumption. It is shown that each of used atomization techniques provides a comparable number of liquid fragments on average, considering the amount of power required. Several techniques for combined atomization are proposed, based on the investigated approaches.
\end{abstract}

Keywords: secondary atomization; fragmentation; interaction between droplets; wall and air jet impact; micro-explosion; child-droplets.

\title{
Nomenclature
}

$n$ - number of child-droplets;

$P$ - power consumed, $\mathrm{kW} / \mathrm{h}$;

$Q_{\mathrm{c}}$ - convective heat flux, $\mathrm{kW} / \mathrm{m}^{2}$;

$R_{\mathrm{d}}$ - droplet radius, $\mathrm{mm}$;

$\mathrm{R}_{\mathrm{d} 1}$ - radii of the first droplet, $\mathrm{mm}$;

$\mathrm{R}_{\mathrm{d} 2}$ - radii of the second droplet, mm;

$r_{\mathrm{d}}$ - average radius of child-droplets, $\mathrm{mm}$;

$S_{0}$ - total surface area of pre-collision droplets, $\mathrm{m}^{2}$;

$S_{1}-$ total surface area of post-collision droplets, $\mathrm{m}^{2}$; 
$t$ - time of initial droplets' breakup into an aerosol, s;

$T_{\mathrm{d}}$ - initial temperature of the composition, ${ }^{\circ} \mathrm{C}$;

$U_{1}, U_{2}$ - first and second droplets velocities before collision, $\mathrm{m} / \mathrm{s}$;

$U_{\mathrm{d}}-$ relative droplet velocity, $\mathrm{m} / \mathrm{s}$;

We - Weber number;

$\alpha_{\mathrm{d}}$ - impact angle, ${ }^{\circ}$;

$\rho_{\mathrm{d}}$ - liquid density, $\mathrm{kg} / \mathrm{m}^{3}$;

$\rho_{\mathrm{g}}$ - gas (air) density, $\mathrm{kg} / \mathrm{m}^{3}$;

$\sigma$ - surface tension, $\mathrm{N} / \mathrm{m}$;

$\mu$ - dynamic viscosity, $\mathrm{Pa} \cdot \mathrm{s}$;

$\tau$ - dimensionless time of initial droplets' breakup into an aerosol.

\section{Introduction}

In most technologies, liquid droplet atomization is aimed to increase the interfacial area as well as inter-component interfaces for heterogeneous compositions [1]. It is especially important to increase this parameter when evaporating or burning impurities, as well as in fire suppression systems, heat and mass transfer plants, for liquid fuel injection, etc. As a result, it is possible to minimize power consumption and the duration of corresponding technological stage in the aforementioned applications due to extensive phase transformation, gas-phase and heterogeneous chemical reaction. Another application for surface treatment processes is thermal plasma spraying. In this case, heterogeneous drops made of 10-100 nm solid nanoparticles in a carrier liquid (water or ethanol) undergo fragmentation when surrounded by a hightemperature, high-velocity plasma jet [2].

Besides the primary atomization of liquid droplets, implemented by various injectors, capillaries, and compressors, quite widespread is a secondary atomization, which is normally based on various physical principles and mechanisms [1]. The first of the typical and most commonly applied schemes is the secondary atomization through droplet collision with a solid surface [4-8]. It is determined [4-8] that interaction time of the droplet and the surface depends on the roughness of the latter. When We number is increased to 60, the impact with a solid surface destroys the droplet, generating a large number of smaller liquid fragments. For We number less than 30 the droplet bounces off a surface, and for a range of We from 50 to 80, the droplet impact creates a thin film on the solid surface, which then breaks up into smaller fragments. The level of droplet disruption is heavily dependent on surface characteristics (roughness, thermal and physical characteristics, hydrophilic or hydrophobic properties, etc.) as well as on liquid viscosity, wall temperature, and impact angle. For instance, higher wall temperature will provide a considerable shift in the transition boundary (in terms of critical size or velocity) between three atomization modes [4-8]: partial fragmentation, explosive disruption, and recurrent bounce followed by breakup. The most rapid breakup occurs in limited heating temperature range of 100 to $300{ }^{\circ} \mathrm{C}$. 
As part of secondary atomization schemes, several liquid aerosol sprays are often intermixed under various angles by intersecting injector spray cones, in order to stimulate droplet collisions. In this case, the rate of droplet breakup depends heavily on the impact angle and We number, as well as on the liquid properties (viscosity, density, and surface tension). The most important thing to determine here is the conditions providing the increase in the number of smaller fragments due to collisions of initial droplets and the effect of the above parameters $[9,10]$.

It is determined [11] that fuel droplets are heavily deformed and break up due to the divergent aerodynamic forces during the secondary atomization. Droplet relative velocity in a gas environment determines the aerodynamic force of droplet deformation, while viscosity (internal friction) and surface tension are the factors that slow down the transformation. The most important dimensionless numbers influencing the droplet breakup are Weber, Ohnesorge, Laplace, Reynolds, and capillary numbers, as well as density and viscosity ratios of two environments (gas and liquid). Studying these forces and effects provided us with thorough knowledge of how droplets of different homogeneous liquids atomize in a gas flow [11]. Breakup conditions are defined for droplets rapidly moving in the air flow and for droplets with the air flow incoming on them.

Droplet atomization can also be stimulated by heat due to the overheating of the low-boiling component. This way we can obtain a fine aerosol with a greatly increased evaporation surface area due to micro-explosive breakup [12-16]. This atomization scheme involves supplying significant heat fluxes by conductive, convective, and radiative heating, as well as complex mixed energy supply to a droplet. In the lab, the main applicable schemes are the extensive convective, conductive and radiative heating of liquid droplets. The convective scheme is characterized by medium value of critical heat fluxes required for extensive droplet aerosol atomization [16], whereas the conductive one is more suited to individual emulsion drop study, providing a shorter micro-explosion delay. An important condition of massive droplet micro-explosive breakup is at least two components in the droplet composition with considerably different boiling temperatures and phase transition heat. The most common composition uses water as a low-boiling component, mixed with combustible liquids, fuels, solid particles, waste. Multi-component compositions of the above are also common [16]. Concerning laboratory experiments using a single emulsion drop, waterin-oil emulsion drops are used in studies $[17,18]$.

Another widely used droplet flow atomization scheme introduces a high-density liquid. For instance, when a lower density liquid flow is moving in a high-density flow, the lighter liquid is affected by a complimentary pressure that leads to atomization or partial fragmentation [19]. This scheme is economically inefficient when building industrial facilities, and the probability of complete droplet breakup during atomization is low. The droplet does not necessarily break up. For instance, low velocity droplet flow $(\mathrm{We}<50)$ does not overcome the surface tension, and the droplet does not disperse even under heavy surface deformation. 
A droplet atomization scheme with gas flow injection [19] is proposed for various fuel combustion devices. The scheme is characterized by high probability of droplet fragmentation, but also by gas (air) oversupply in the combustion chamber, increasing both economic expenses and the generated nitrogen dioxide concentration. It is known [20] that high velocity of droplet flow leads to droplet fragmentation due to friction and resistance domination over the surface tension. However, this scheme is economically inefficient because the chambers and heat exchangers need to be pressurized, which increases their cost and wear. In the field of surface coating, a liquid jet is injected into a plasma jet where it undergoes a first fragmentation into liquid drops, which in turn undergo their secondary atomization [2], also by means of the surrounding gas phase momentum.

An interesting possibility here is to combine several primary and secondary atomization schemes, with a possible decrease in cost and time needed to generate a droplet aerosol of the required fineness. There is no comparative data yet on the integral characteristics of droplet breakup for different liquid compositions in every known secondary atomization scheme. The main obstacle seems to be the absence of common comparative criteria due to a drastic difference in physical origin of atomization in the above mentioned schemes. As a first step, it is reasonable to compare the integral characteristics of atomization by determining the average and maximum size of liquid fragments generated, their total surface area or total volume occupied. Next, we need to evaluate the amount of energy required to obtain the identical parameters, mentioned above, for each secondary atomization scheme. Another promising objective is to find a combination of several secondary atomization schemes for different liquids. Considering the results of experimental studies [1, 3-13], we can safely assume that atomization schemes with droplet collisions, collision (impact) with a wall, and incoming air flow are more promising for heterogeneous droplets. Microexplosive breakup by overheating and boiling is important for inhomogeneous droplets.

The aim of this research is to compare the droplet atomization characteristics for different liquids by stimulating droplet collisions, impact with an obstacle (solid surface), droplet acceleration in the air flow (or by intense incoming gas jet), and micro-explosive breakup.

\section{Experimental Procedures}

We used several experimental setups and recording techniques for this research. The different schemes of atomization are presented in Fig. 1. Each setup design was based on the phenomenological approach using only isolated droplets as an object under study in the recording area. We have not yet considered the synergy effects of adjacent droplets inside the aerosol flow. To study droplet collisions, we used the setup fitted with a droplet generator and a liquid supply system. The experimental parameters were recorded in the same way as in studies $[9,10]$. The liquid supply system consists of a submersible pump with variable performance (1.2 to $1.6 \mathrm{l} / \mathrm{min}$ ) and two silicone capillaries connected to specially designed nozzles (droplet generators) fixed to a holder ring. Droplet size was varied from 0.3 to $1.5 \mathrm{~mm}$ with the help of interchangeable nozzles. Impact angle $\left(\alpha_{d}\right)$ was varied from 0 to $90^{\circ}$ by changing their position in 
the holder ring. By varying the pump performance, we changed the droplets velocities $\left(U_{\mathrm{d} 1}, U_{\mathrm{d} 2}\right)$. To produce the interaction regime maps, we calculated the Weber numbers of the droplets closing in before collision, considering their relative velocity $\left(U_{\mathrm{rel}}=\left(U_{\mathrm{d} 1}{ }^{2}+U_{\mathrm{d} 2}{ }^{2}-2\left|U_{\mathrm{d} 1}\right| \cdot\left|U_{\mathrm{d} 2}\right| \cdot \cos \left(\alpha_{\mathrm{d}}\right)\right)^{0.5}\right)$ and radius of small $\operatorname{droplet}\left(R_{\mathrm{d} 1}\right): \mathrm{We}=2 \cdot R_{\mathrm{d} 1} \cdot \rho \cdot U_{\mathrm{rel}}^{2} / \sigma$.

In preliminary tests, we used a pair of high-speed video cameras (resolution 1152x864, frequency 3000 to $100000 \mathrm{fps}$ ) to capture the droplet size, velocity, angle, shape, and the number of fragments, as well as to determine the interaction regimes. The observation area was lit by several light screens. The cameras were located at an angle of $90^{\circ}$ relative to each other to reproduce the spatial pattern. Two elements of a lighting system were opposite the cameras to enhance droplets image quality. Each camera was used for 2dimensional recording as shown in Figs. 1 and 2. A focus depth was from $5 \mathrm{~mm}$ to $15 \mathrm{~mm}$ for the cameras. To determine the focus depth, the Multi-Function Calibration Target (for Low Magnification Systems) was applied. In preliminary experiments, manual focusing was used for the subsequent calculation of scale and correction factors. Methods of measuring the primary droplets size, velocity and impact angles, as well as the number, size, and velocities of the secondary droplets, are based on the processing of videograms, the applying of a coordinate grid (collisions - from 25x32 mm to 31x38 mm; wall impact - from 25x34 mm to 27x36 mm; air jet impact - from 220x270 mm to 330x274 mm; micro-explosive breakup by overheating from 14x14 mm to 17x17 mm) and the scale factors (collisions - from $0.025 \mathrm{~mm} / \mathrm{px}$ to $0.032 \mathrm{~mm} / \mathrm{px}$; wall impact - from $0.025 \mathrm{~mm} / \mathrm{px}$ to $0.029 \mathrm{~mm} / \mathrm{px}$; air jet impact - from $0.25 \mathrm{~mm} / \mathrm{px}$ to $0.31 \mathrm{~mm} / \mathrm{px}$; microexplosive breakup by overheating - from $0.018 \mathrm{~mm} / \mathrm{px}$ to $0.023 \mathrm{~mm} / \mathrm{px}$ ).

For processing the videograms, the Tema Automotive and FastCam software were applied. The software allowed to analyze the position of droplets, their velocities, accelerations, impact angles and covered distances with a high temporal sampling. The Tema Automotive software used the following functions: scaling/coordinate systems; analysis properties like position, velocity, acceleration, and angle are automatically calculated for all points in the session; automatic tracking; semi-automatic tracking; manual; time panel; time panel; graphs and tables panel. The FastCam software involved the use of the following functions: display scale; angle measurement; measuring distance between the two points; analysis. Markers allowing to track objects were used for the subsequent calculation of velocity, size, and impact angle (Fig. 1).

To determine the parameters characterizing the droplet fragmentation outcomes, the ratio between the surface areas of the emerged child-droplets and the two initial primary drops $\left(S_{1} / S_{0}\right)$ was calculated. The surface area of the initial droplets, e.g., in the experiments with droplets collisions, was calculated using the formula: $S_{0}=4 \cdot \pi \cdot\left(R_{\mathrm{d} 1}^{2}+R_{\mathrm{d} 2}{ }^{2}\right)$. When determining the surface area of the child-droplets, the size of all these droplets $\left(r_{\mathrm{di}}\right)$ and their number $(N)$ were considered using the formula $S_{1}=4 \cdot \pi \cdot \sum N \cdot r_{\mathrm{di}}{ }^{2}$. Since not all newly emerged secondary droplets were in the recording area, a correction factor (0.15-0.76) was introduced for the number of child-droplets. The number of apparent $\left(N_{\mathrm{ti}}\right)$ and invisible $\left(N_{\mathrm{tv}}\right)$ droplets was determined. The latter $\left(N_{\mathrm{tv}}\right)$ should be considered to ensure equality of the volumes of the droplets before 
and after the interaction. The number and size of the invisible droplets were estimated on the basis of the assumption of the spatial homogeneity of the scattering of child-droplets during primary droplets collision. Following this assumption, if there is a two-dimensional distribution, the spatial one can be reliably predicted. The experiments have shown that the number and mean size of the secondary droplets in the case of single camera use and spatial homogeneity assumption differed from the analogous parameters recorded using a pair of cameras by 8-13\%. Considering such insignificant differences, it was decided to use further the results obtained using a single camera.

Systematic error for all of the experiments was: $1.6 \%$ for droplet radius measurement, $2.1 \%$ for droplet velocity measurement, $3 \%$ for air flow velocity measurement, and $2.3 \%$ for impact angle measurement. Random error will be shown as a confidence interval in the curves.

To study the droplet collision with a solid surface, we used the setup fitted with a liquid tank and a dispenser (droplet generator). Droplets fell free from the dispenser onto the solid surface - a copper plate also referred to as a wall or an obstacle. The plate was fixed on a holder. The droplet impact angle to the surface was varied by changing the plate position on the holder. Plates of different characteristics (roughness, thermal and physical characteristics, hydrophilic and hydrophobic properties, temperature, etc.) could be fixed on the holder. The experimental parameters were recorded in the same way as in studies [38]. The experiments enabled to observe the size and number change of the secondary droplets emerged because of the collision of the primary droplets with a wall during liquid film formation on the wall surface. These issues were well learned within a number of experimental and theoretical studies [4-8]. Next, the mean amount and size of the secondary droplets detected in the tests with the primary droplets colliding with a wall will be discussed. In this case, a set of the tests, during which the primary droplets successively collided with a wall, forming the liquid film, was implemented. After performing this experiment during one minute, the number and size of the secondary droplets were averaged. In the future, it is planned to learn in detail the effect of these peculiarities on the values of $S_{1} / S_{0}$.

To study the droplet micro-explosion during high-temperature convective heating, we released a droplet into a vertically positioned rotary muffle furnace (temperature range $20-1200{ }^{\circ} \mathrm{C}$ ). Dispensers were used to generate droplets of 0.62 to $1.34 \mathrm{~mm}$ in size. Furnace temperature was recorded by a system of National Instruments data collection module and fast thermocouples (accuracy $\pm 3{ }^{\circ} \mathrm{C}$, response $0.1 \mathrm{~s}$ ). The measurement technique is similar to the one used in study [16]. Mura et al. [17] studied an individual emulsion drop sliding onto a $5.71 \mathrm{~mm}$-diameter heated plate, by means of the Leidenfrost effect. The heated plate was maintained at the temperature of $363{ }^{\circ} \mathrm{C}$, providing a conductive heat transfer to the emulsion drop. A fast (10 kHz) CMOS camera LAVision High Speed-Star 6 with a $60 \mathrm{~mm}$ objective was used to visualize and count the child-droplets issued from the micro-explosion. Watanabe et al. [18] expose the thermocouple-suspended drop of emulsified fuel to both convective and radiative heating, within an electric furnace where wall temperature is set to $700{ }^{\circ} \mathrm{C}$ and air temperature is set to $577^{\circ} \mathrm{C}$. From these three sets of experimental data, we derive the micro-explosion behavior of emulsified fuel drops undergoing the three 
modes of heat transfer. Generally speaking, convective and radiative heat transfer are more representative of spray combustion applications, whereas conductive heat transfer is used in the lab to closely observe an individual emulsion drop.

To study the isolated droplet interaction with an air jet, we used a setup with an atmospheric pressure liquid tank. The lower part of the tank is connected to a dispenser tip via an elastic tube with a roller clamp. Opening the roller clamp generated a droplet of required size at the tip of the dispenser. At a 0.4 m distance from the dispenser, a narrow $(10 \mathrm{~mm})$ nozzle is mounted. When a shutter opened in front of the nozzle, a short burst of air flow occurred, aimed at the downward droplet. The air flow velocity was recorded by a hot-wire anemometer (accuracy $0.3 \mathrm{~m} / \mathrm{s}$, measuring range 0-60 m/s) and varied in the range of 2 to $45 \mathrm{~m} / \mathrm{s}$ for all of the experiments. The experimental parameters were recorded in the same way as in study [10]. Damiani et al. [2] studied the secondary atomization of pure water drops within a high-temperature (up to $\left.13727^{\circ} \mathrm{C}\right)$, high-velocity (1000-3000 m/s) plasma jet issued from a SULZER F4 plasma gun with an anode diameter of $6 \mathrm{~mm}$. A CMOS fast camera PHOTRON Fastcam SA 1.1 was used to record the spray images at the acquisition frequency of $20 \mathrm{kHz}$. This was necessary to measure the sizes of the drops fragmented by the surrounding plasma jet. The experimental set-up and parameters are fully documented in study [2].

We researched the compositions (Table 1) that are typical of the practical applications, mentioned in the Introduction Section. Graphite particles were used to compose slurries, because it is the most common ingredient of firefighting compositions. Among the solutions of environmental and energy problems there is an implementation of vegetable oil-based fuel. In countries with temperate climate, rapeseed oil-based fuel is considered the most efficient. Given that, we used rapeseed oil emulsion for our experiments. We chose diesel for our experiments for its wide usage in every industry, especially as internal combustion engine and power plant fuel. The main physical properties of components and liquid compositions are shown in Table 2. It also gives the key characteristics describing the reasons for surface transformation and droplet fragmentation in the reported secondary atomization schemes.

\section{Results and Discussion}

\subsection{General patterns and aspects of droplet breakup modes}

Figs. 2 and 3 demonstrate typical experimental video frames to illustrate general and particular modes of droplet breakup during each of the used secondary atomization schemes, and data from study [17]. In terms of the shape sequence of breaking droplets, we can distinguish three types. The first one is characterized by considerable droplet surface deformation while maintaining its integrity, the growth of its maximum size due to the aerodynamic force, and the following breakup into a small number of relatively large fragments. In the second one, fragments separate from a dispersing droplet (referred to as partial fragmentation). The third one is the complete droplet breakup to form a fine aerosol. The higher the inertia, the more often the third scenario of droplet breakup occurs. The third type is the most desirable for the practical applications since it provides droplet fragments that are significantly smaller than the original 
droplets (Fig. 2) formed by a spray nozzle, dispenser, compressor or sprinkler. Fragmentation by means of the surrounding plasma jet (photos shown in Fig. 4 of study [2]) is also an example of the third shape sequence of break-up, referred to as "sheet stripping" fragmentation regime (fifth secondary atomization scheme) in the Weber number interval $100 \leq \mathrm{We} \leq 350$.

All schemes of droplet interaction are characterized by the significant transformation and increased size of the droplet and thinner near-surface layers prior to the imminent breakup. Each of used approaches has different physical reasons, factors and mechanisms leading to the droplet size increase prior to the breakup. For instance, in the case of micro-explosive breakup, the droplet size increases due to inner vapor bubbles. The pressure growth in the bubbles leads to the thinning of the liquid surface film, and the droplet breaks up when the critical pressure is reached. In the case of droplet collisions, impact with a wall or with a gas jet, a shift in droplet layers is observed, with considerable distortion of its spherical shape. This leads to droplet surface instability due to the increasing aerodynamic forces. In particular, the shape of distorted droplets was near-elliptical, or even disc-like. The drag coefficient of these shapes is $30-50 \%$ higher than that of a sphere. Therefore, the lifetime of these droplets for the same Weber number (i.e., velocity and size) is shorter than that of a sphere. Molecular bonds in the droplet are affected considerably by acceleration and heating. This is why we observed variations in the decrement of the relative size of droplet fragments and increment of the total surface area for the same We numbers or durations (Figs. 4 and 5).

The inhomogeneous droplet micro-explosive breakup characteristics are dependent not only on temperature, but also on the velocity of heating gases. The latter is the definitive factor of heat flux calculation. That is why in the comparative analysis of atomization characteristics in Figs. 4 and 5 there are curves of $r_{\mathrm{d}} / R_{\mathrm{d}}$ and $S_{1} / S_{0}$ versus We and $Q_{\mathrm{c}}$ as functions of droplet velocity in a gas environment. The chosen threshold heat fluxes were to ensure the stable disruption mode. A partial droplet fragmentation scenario was typical of $Q_{\mathrm{c}}$ lower than those presented in this work. It demonstrated a long-lasting process of droplet disruption (2-3 to 15-20 seconds) resulting in quite large liquid fragments, often polydisperse ones. This atomization mode is deemed inapplicable for it demands longer droplet heating. Experiments [12-16] demonstrate principal differences in droplet disruption characteristics between partial fragmentation and micro-explosive breakup scenarios. Basing on these results, at a high concentration of droplets in the gas environment, their partial fragmentation will not have any significant effect on aerosol particle size distribution due to coalescence, bounce, and separation of generated fragments. Only with the low concentration of initial droplets in aerosol and longer droplet travel time, the $S_{1} / S_{0}$ can be increased up to 3-5 times by partial fragmentation. There are some rare cases when these conditions may occur. For example, in firefighting, the droplet aerosol travel time from the drop zone to the surface of thermally decomposing materials is several minutes. The concentration of atomized droplets remains low due to smaller droplets being entrained by up going high-temperature combustion product flow.

Figs. 4 and 5 show that micro-explosive breakup can be ensured in a wide range of both temperature or heat flux, and duration. At relatively low heat fluxes, the duration of initial droplet disruption can be 10 
times longer than in the three impact schemes of atomization. Figs. 4 and 5 show that in terms of atomization time, as well as $r_{\mathrm{d}} / R_{\mathrm{d}}$ and $S_{1} / S_{0}$, at higher (over $100{ }^{\circ} \mathrm{C}$ ) heating temperature, the micro-explosive breakup scheme becomes the most desirable one. It is the two components with different boiling temperature that become the definitive factor of breakup stimulation. The higher this difference, the greater the breakup stimulation even at relatively low incoming heat flux [16]. Among the three other schemes - droplet interaction with the wall, with the adjacent droplet, or with the air flow - for equal Weber numbers, wall impact takes the shortest time. Comparative analysis shows that the higher the density and viscosity of liquid, the smaller the difference between droplet breakup duration for droplet collisions and wall impact. Friction and inertia will have a close effect, especially considering the interaction of hundreds of droplets with the wall. In this case, every droplet impact creates a thin film on the wall surface that will run off. The conditions of impact scenario are close to those of the droplet collision scheme, especially at high velocity and impact angle of $60-90^{\circ}$. That is why relatively close breakup duration, minimum fragment size, and total surface area were recorded under the convective mode of heat transfer (Figs. 4 and 5). The conductive mode of heat transfer to the emulsion drop (Mura et al. [17]) enables a faster atomization of the emulsion drop (within less than $0.03 \mathrm{~s}$ ). This reported decrease of diameter is actually the average of the same experiment repeated 4 times. It illustrates the case of an optimized micro-explosion, concerning an emulsion drop having a doubled diameter compared to results $(1,2,3,4)$ under convective heat. After a longer heating time as long as $1 \mathrm{~s}$, Watanabe et al. [18] observe a disintegration of the 0.7-1.3 mm diameter emulsion drop over a duration of $0.5 \mathrm{~s}$., in an electric furnace providing most of its heat as radiation.

Fig. 5 clearly shows that at We $>100$ we can achieve quite high $S_{1} / S_{0}$ by hitting the droplet with an air jet. Unlike in the droplet collision or impact schemes, there is no counter flowing liquid that would lead to a possibility of coalescence, increasing the fragment size $r_{\mathrm{d}}$, and decreasing the total surface area $S$. Even at high velocities, the layers of colliding droplets due to high viscosity will produce large fragments when intermixing, especially in the case of coaxial collisions or droplet-to-wall interactions. Air jet impact on the droplet distends the latter, creating a number of liquid arrays, which afterwards are torn into a large amount of smaller fragments. No coagulation was recorded due to the unidirectional motion, hence the higher $S_{1} / S_{0}$ (Fig. 5). Under the blow of a plasma jet [2], the "sheet stripping" fragmentation regime in the Weber number interval $100 \leq \mathrm{We} \leq 350$ is interestingly in the same order of magnitude than the other reported results of micro-explosion and air jet impact.

For each droplet interaction scheme (droplet collision, wall impact, and air jet impact), certain conditions are determined when $S_{1} / S_{0}$ as a function of We reaches an asymptote (Fig. 5). This illustrates the existence of asymptotic relation between inertia, viscosity (internal friction), and surface tension forces for the impact schemes of secondary atomization. There was an indication of such an asymptote in microexplosive droplet breakup experiments, though not in every experiment and not for every component composition. Most likely, the concentration of low-boiling component and droplet heating method have a crucial role here, being the defining factors of $S_{1} / S_{0}[12]$. 


\subsection{Comparing the necessary and sufficient conditions}

It is of special interest to determine the necessary and sufficient conditions (Figs. 5 and 6) of droplet disruption for different schemes of secondary atomization. The corresponding conditions for different liquid compositions are determined in studies [1, 3-13]. Antonov et al. [16] summarized the boundary conditions of inhomogeneous droplet atomization through micro-explosive breakup as a result of conductive, convective, and radiative heating. A high-potential task is to evaluate the amount of energy necessary and sufficient to obtain the identical number of smaller liquid fragments. The number and size of fragments can be evaluated using the distributions and curves in Figs. 4 and 5. Different ways of energy supply can be implemented in each of the secondary atomization schemes. First, we need to calculate the amount of electrical energy required for liquid flow and air flow generation, as well as for droplet heating. Fig. 6 shows the calculated amount of energy necessary and sufficient to obtain the $r_{\mathrm{d}} / R_{\mathrm{d}}$ and $S_{1} / S_{0}$ shown in Figs. 4 and 5.

From Fig. $6 a$ it is clear that the micro-explosive breakup scheme provides maximum $S_{1} / S_{0}$ and requires maximum electric energy for muffle heating. Considering the ratios of breakup parameters (for instance, $S_{1} / S_{0}$ ) to the required energy amount (i.e., to obtain specific characteristics of the secondary atomization), the advantages of micro-explosive scheme are not that substantial comparing to the others. In terms of specific characteristics, the difference will comprise 20 to $60 \%$. Given that micro-explosive breakup provides maximum $S_{1} / S_{0}$ in the case of considerable droplet composition inhomogeneity [12], it will not demonstrate any significant increase in $S_{1} / S_{0}$ and corresponding decrease in $r_{\mathrm{d}} / R_{\mathrm{d}}$ when atomizing homogeneous droplets (water in particular).

Using the technique from study [21], we have calculated the dimensionless time (duration) of breakup (secondary atomization) for all the four interaction schemes of liquid droplets $\left(\tau=t \cdot U_{\mathrm{d}} \cdot\left(\rho_{\mathrm{g}} / \rho_{\mathrm{d}}\right)^{0.5} / 2 R_{\mathrm{d}}\right)$. Fig. $6 b$ shows that the secondary atomization time can be varied in a wide range by changing the droplet interaction scheme. Efficient ratios between $S_{1} / S_{0}$ and $\tau$ can be chosen as well, considering Fig. 6.

To calculate the amount of energy spent for droplet atomization in different schemes, we considered the energy required for an hour-worth hardware operation (heating chamber, air compressor, etc.). For the micro-explosive breakup scenario, we considered the second hour of the setup operation, since it takes about 40 to 60 minutes to heat up the muffle furnace. The calculated surface area ratio is a mean average from the whole operation of the setup. Size and velocity are similar for all the four schemes, meaning that we can compare the experimental results for similar We numbers. Hardware technical documentation for the air compressor and water pump mentions $7.5 \mathrm{~kW} / \mathrm{h}$ consumed power at 10 bar pressure and $1.1 \mathrm{~kW} / \mathrm{h}$ at 1 bar pressure. The power was chosen based on the required pressure. To heat the muffle furnace up to $1100{ }^{\circ} \mathrm{C}$, about $2000 \mathrm{~kW}$ of power is needed. This data was used to calculate the required power and to plot the curves in Fig. 6. 
Fig. 6 demonstrates that the secondary atomization scheme with significant droplet overheating requires the highest energy consumption, as expected. The comparative analysis provides us with several important findings. First, calculation results in Fig. 6 are shown disregarding the amount of simultaneously atomized droplets. It is clear that in the case of impact schemes, i.e., droplet collision, wall or air jet impact, the droplet concentration in aerosol will play an important role. In the case of high-temperature droplet heating, the dispersion and breakup occur with no significant interference from adjacent droplets [16]. Thus, considering the number of simultaneously atomized droplets, the micro-explosive scheme will be far less expensive than in the case of a single isolated droplet. Second, when comparing the impact atomization schemes, we can see a close amount of required energy. In terms of engineering aspects, the droplet collision scheme as well as droplet and wall (including a heated one) interaction scheme can be considered the simplest ones. The implementation of these two schemes looks more efficient comparing to the air jet impact scheme. Third, the $S_{1} / S_{0}$ differences do not change much with an increase in the Weber number and thermal flux density. This means that Fig. 6 can be used to predict $S_{1} / S_{0}$ when droplet velocity and size, as well as heating temperature are varied in a wide range for the four secondary atomization schemes under study.

The result of the comparative analysis predicts considerable energy savings if several secondary atomization schemes are combined. For example, injecting several liquid jets at an impact angle of 60 to $90^{\circ}$ to each other can decrease the size of droplets by 5-7 times due to their collisions. Then the falling fragments can be dispersed even more by placing walls, meshes, edges, and other types of obstacles to implement the wall impact scheme of atomization. A heater can be placed in the lower portion of the atomization chamber, overheating the falling fragments to their boiling temperatures and causing further breakup. Such a combination provides substantial thermal and electric energy savings. The initial droplet size prior to the micro-dispersion will be 10-30 times smaller than the ones used in the described experiments with fragmentation through droplet collisions, wall impact or air jet impact. The resulting curves and diagrams form the original experimental database for efficiency evaluation and further development of physical and mathematical predictive models (in particular, [22-27]).

The analysis of the research presented in this paper and the data from studies [1, 3-13] brings us to a conclusion that the synergistic effects provided by a combination of any of the four schemes under study can be studied reliably through experimental research only. There are several reasons for it. First, in the case of high-temperature heating of the gas environment and droplets, we should consider the vapor buffer layer formed around the latter. It constrains the surface transformation and lowers the heat flux, changing the heat exchange conditions. No reliable models have yet been developed to describe these conditions, especially if the heating temperature exceeds $500{ }^{\circ} \mathrm{C}$. Second, liquid fragments generated by droplet collisions or impact with a wall usually form a cloud that is polydisperse in terms of size. Further disruption of this cloud is difficult to describe in detail. Third, the incoming gas jet deforms the droplet into a shape 
that is difficult to describe mathematically without significant computational resources. All the three above mentioned problems mean that there is no sufficient base yet for rigorous mathematical modeling.

We analyzed the experimental results in terms of the two traditional assessment criteria for newly designed system or technology: quality and efficiency. This brought us to a conclusion that the microexplosive atomization scheme, being mostly thermal, has the greatest potential in internal combustion engines and other advanced power machinery. The advantage of this scheme over the other three, which are mostly gas-dynamic, can be described as follows. Any gas-dynamic technology can only be implemented in a combustion chamber with additional hardware for air compressing, which is not readily available in contemporary engine designs. At the same time, the energy produced by the engine itself or by fuel combustion power facility cannot be spent for droplet vaporization or its breakup by a gas jet. So, it demands an additional power source and hardware for droplet and gas propelling. However, the thermal micro-explosive scheme can be implemented using the immediately available heat from fuel combustion that is removed for engine cooling. No additional power sources will be needed when utilizing the excess heat, just like in other heat and power industry technologies, and about $250-350{ }^{\circ} \mathrm{C}$ will be enough for the micro-explosive atomization. In this regard, the secondary micro-explosive atomization technology will have a clear advantage over any other droplet disruption scheme for traditional fuels, slurries or emulsions [28-31].

\section{Conclusions}

(i) The experiments allowed us to determine the integral characteristics of droplet size and total surface area variation, as well as disruption time for the most commonly used secondary atomization schemes. We gathered enough experimental data to consider the three modes of heat transfer to the emulsion drop leading to its micro-explosion, and also its disruption under plasma jet impact in the "sheet stripping" disruption regime. The comparative analysis revealed a several-fold advantage of the heated droplet microexplosion scheme in terms of these parameters. Droplet size can be decreased 3-10 times depending on the density of the supplied heat flux. Minimum breakup duration can reach 10-20 ms. Total liquid surface area increases 60-100 times.

(ii) In terms of minimum required power for the secondary atomization, micro-dispersion requires the most. The amount of energy required is several or even more than 10 times higher than in the case of collisions, wall impact or air jet impact schemes. Overall, considering the surface area growth and the required amount of smaller liquid fragments, all the five schemes are practicable. However, the droplet micro-explosion and collision schemes have preference, since their efficiency has little dependence on the number and concentration of simultaneously injected droplets.

(iii) The most promising direction for the development of the results presented in this paper is the combined secondary atomization approach by consecutive application of two or three schemes based on different mechanical and physical ways of droplet disruption. For homogeneous droplets, the most practical 
combination is droplet collisions at the first stage followed by the impact of the generated fragments with the wall. This combination increases the $S_{1} / S_{0}$ ratio several-fold. For inhomogeneous droplets, the most promising combination is droplet collision or wall impact at the first stage. After that, the resulting liquid fragments are heated to the boiling temperature followed by micro-explosive breakup. This combination increases the $S_{1} / S_{0}$ ratio more than 100 times. The air jet impact scheme of droplet disruption can be recommended as an option if need be. This is because in this scenario the generated liquid fragments may stick to the chamber wall opposing the air jet direction, or coalesce with the incoming droplet flow. The parameters of secondary atomization will be heavily dependent on the droplet generation technique. In the case of large-scale aerosol flow, generated by the primary liquid atomization, it is difficult to vary the droplet parameters in a wide range in different sections of the aerosol cloud.

\section{Acknowledgments}

Research was supported by the Russian Science Foundation (project 18-71-10002).

\section{References}

1. O.V Vysokomornaya, M.V Piskunov, P.A. Strizhak, Breakup of heterogeneous water drop immersed in high-temperature air, Appl. Therm. Eng. $127 \quad$ (2017) 1340-1345. doi:https://doi.org/10.1016/j.applthermaleng.2017.08.162.

2. D. Damiani, D. Tarlet, E. Meillot, A Particle-Tracking-Velocimetry (PTV) Investigation of Liquid Injection in a DC Plasma Jet, J. Therm. Spray Technol. 23 (2014) 340-353. doi:10.1007/s11666-0130050-5.

3. E.-S.R. Negeed, N. Ishihara, K. Tagashira, S. Hidaka, M. Kohno, Y. Takata, Experimental study on the effect of surface conditions on evaporation of sprayed liquid droplet, Int. J. Therm. Sci. 49 (2010) 2250-2271. doi:https://doi.org/10.1016/j.ijthermalsci.2010.08.008.

4. T.-S. Zen, F.-C. Chou, J.-L. Ma, Ethanol drop impact on an inclined moving surface, Int. Commun. $\begin{array}{lllll}\text { Heat } & \text { Mass } & \text { Transf. } & 37 & \text { (2010) }\end{array}$ doi:https://doi.org/10.1016/j.icheatmasstransfer.2010.05.003.

5. G. Liang, Y. Guo, Y. Yang, S. Shen, Liquid sheet behaviors during a drop impact on wetted cylindrical surfaces, Int. Commun. Heat Mass Transf. $54 \quad$ (2014) 67-74. doi:https://doi.org/10.1016/j.icheatmasstransfer.2014.03.010.

6. G. Liang, I. Mudawar, Review of mass and momentum interactions during drop impact on a liquid film, Int. J. Heat Mass Transf. $101 \quad$ (2016) 577-599. doi:https://doi.org/10.1016/j.ijheatmasstransfer.2016.05.062.

7. C. Josserand, S.T. Thoroddsen, Drop Impact on a Solid Surface, Annu. Rev. Fluid Mech. 48 (2016) 365-391. doi:10.1146/annurev-fluid-122414-034401. 
8. G. Liang, I. Mudawar, Review of drop impact on heated walls, Int. J. Heat Mass Transf. 106 (2017) 103-126. doi:10.1016/j.ijheatmasstransfer.2016.10.031.

9. M. Szakáll, I. Urbich, Wind tunnel study on the size distribution of droplets after collision induced breakup of levitating water drops, Atmos. Res. 213 (2018) 51-56. doi:10.1016/j.atmosres.2018.05.007.

10. C.-K. Kuan, K.-L. Pan, W. Shyy, Study on high-Weber-number droplet collision by a parallel, adaptive interface-tracking method, J. Fluid Mech. 759 (2014) 104-133. doi:10.1017/jfm.2014.558.

11. A.M. Ithnin, H. Noge, H.A. Kadir, W. Jazair, An overview of utilizing water-in-diesel emulsion fuel in diesel engine and its potential research study, J. Energy Inst. 87 (2014) 273-288. doi:https://doi.org/10.1016/j.joei.2014.04.002.

12. D. Stefanitsis, I. Malgarinos, G. Strotos, N. Nikolopoulos, E. Kakaras, M. Gavaises, Numerical investigation of the aerodynamic breakup of Diesel and heavy fuel oil droplets, Int. J. Heat Fluid Flow. 68 (2017) 203-215. doi:https://doi.org/10.1016/j.ijheatfluidflow.2017.10.012.

13. S.S. Sazhin, O. Rybdylova, C. Crua, M. Heikal, M.A. Ismael, Z. Nissar, A.R.B.A. Aziz, A simple model for puffing/micro-explosions in water-fuel emulsion droplets, Int. J. Heat Mass Transf. (2019) 815-821. doi:10.1016/j.ijheatmasstransfer.2018.11.065.

14. E. Mura, R. Calabria, V. Califano, P. Massoli, J. Bellettre, Emulsion droplet micro-explosion: Analysis of two experimental approaches, Exp. Therm. Fluid Sci. $56 \quad$ (2014). doi:10.1016/j.expthermflusci.2013.11.020.

15. D.V. Antonov, O.V. Vysokomornaya, M.V. Piskunov, R.M. Fedorenko, W.M. Yan, Influence of solid nontransparent inclusion shape on the breakup time of heterogeneous water drops, Int. Commun. Heat Mass Transf. 101 (2019). doi:10.1016/j.icheatmasstransfer.2018.12.009.

16. D. Antonov, J. Bellettre, D. Tarlet, P. Massoli, O. Vysokomornaya, M. Piskunov, Impact of holder materials on the heating and explosive breakup of two-component droplets, Energies. 11 (2018). doi:10.3390/en11123307.

17. E. Mura, C. Josset, K. Loubar, G. Huchet, J. Bellettre, Effect of dispersed water droplet size in microexplosion phenomenon for water in oil emulsion, At. Sprays. 20 (2010) 791-799. doi:10.1615/AtomizSpr.v20.i9.40

18. H. Watanabe, T. Harada, Y. Matsushita, H. Aoki, T. Miura, The characteristics of puffing of the carbonated emulsified fuel, Int. J. Heat Mass Transf. 52 (2009) 3676-3684. doi:10.1016/j.ijheatmasstransfer.2009.02.033.

19. B.E. Gelfand, Droplet breakup phenomena in flows with velocity lag, Prog. Energy Combust. Sci. 22 (1996) 201-265. doi:https://doi.org/10.1016/S0360-1285(96)00005-6.

20. A.A. Shraiber, A.M. Podvysotsky, V. V Dubrovsky, Deformation and breakup of drops by aerodynamic forces, At. Sprays. 6 (1996) 667-692. doi:10.1615/AtomizSpr.v6.i6.30.

21. H. Zhao, Z. Wu, W. Li, J. Xu, H. Liu, Interaction of two drops in the bag breakup regime by a continuous air jet, Fuel. 236 (2019) 843-850. doi:https://doi.org/10.1016/j.fuel.2018.09.067. 
22. H. Watanabe, Y. Matsushita, H. Aoki, T. Miura, Numerical simulation of emulsified fuel spray combustion with puffing and micro-explosion, Combust. Flame. 157 (2010) 839-852. doi:https://doi.org/10.1016/j.combustflame.2010.01.013.

23. S.S. Sazhin, A.E. Elwardany, P.A. Krutitskii, V. Deprédurand, G. Castanet, F. Lemoine, E.M. Sazhina, M.R. Heikal, Multi-component droplet heating and evaporation: Numerical simulation versus experimental data, Int. J. Therm. Sci. 50 (2011). doi:10.1016/j.ijthermalsci.2011.02.020.

24. G. Strotos, I. Malgarinos, N. Nikolopoulos, M. Gavaises, Numerical investigation of aerodynamic droplet breakup in a high temperature gas environment, Fuel. 181 (2016) 450-462. doi:10.1016/J.FUEL.2016.04.126.

25. K. Warncke, S. Gepperth, B. Sauer, A. Sadiki, J. Janicka, R. Koch, H.-J. Bauer, Experimental and numerical investigation of the primary breakup of an airblasted liquid sheet, Int. J. Multiph. Flow. 91 (2017) 208-224. doi:10.1016/j.ijmultiphaseflow.2016.12.010.

26. N. Liu, Z. Wang, M. Sun, H. Wang, B. Wang, Numerical simulation of liquid droplet breakup in supersonic flows, Acta Astronaut. 145 (2018) 116-130. doi:10.1016/J.ACTAASTRO.2018.01.010.

27. C. Shao, K. Luo, Y. Yang, J. Fan, Direct numerical simulation of droplet breakup in homogeneous isotropic turbulence: The effect of the Weber number, Int. J. Multiph. Flow. 107 (2018) 263-274. doi:10.1016/J.IJMULTIPHASEFLOW.2018.06.009.

28. Y. Morozumi, Y. Saito, Effect of Physical Properties on Microexplosion Occurrence in Water-in-Oil Emulsion Droplets, Energy \& Fuels. 24 (2010) 1854-1859. doi:10.1021/ef9014026.

29. A.M. Ithnin, H. Noge, H.A. Kadir, W. Jazair, An overview of utilizing water-in-diesel emulsion fuel in diesel engine and its potential research study, J. Energy Inst. 87 (2014) 273-288. doi:https://doi.org/10.1016/j.joei.2014.04.002.

30. D. Tarlet, E. Mura, C. Josset, J. Bellettre, C. Allouis, P. Massoli, Distribution of thermal energy of child-droplets issued from an optimal micro-explosion, Int. J. Heat Mass Transf. 77 (2014) 1043-1054. doi:10.1016/j.ijheatmasstransfer.2014.06.054.

31. D. Tarlet, C. Josset, J. Bellettre, Comparison between unique and coalesced water drops in microexplosions scanned by differential calorimetry, Int. J. Heat Mass Transf. 95 (2016) 689-692. doi:10.1016/j.ijheatmasstransfer.2015.12.054. 
Table 1.

Properties of liquid compositions under study (calculated on the basis of component percentage and their characteristics at $25^{\circ} \mathrm{C}$ ).

\begin{tabular}{|l|c|c|c|}
\hline Composition name & Density, $\mathrm{kg} / \mathrm{m}^{3}$ & Surface tension, N/m & Dynamic viscosity, Pa·s \\
\hline Water & 998 & 0.07269 & 0.0014 \\
\hline Graphite slurry (10 wt\%) & 1046 & 0.10903 & 0.0017 \\
\hline Rapeseed oil emulsion (10 vol\%) & 990 & 0.06721 & 0.0098 \\
\hline Diesel fuel emulsion (10 vol\%) & 891 & 0.02077 & 0.0013 \\
\hline Sunflower oil & 865 & 0.03371 & 0.0521 \\
\hline
\end{tabular}

Table 2.

Typical properties of the non-flammable and flammable liquids.

\begin{tabular}{|c|c|c|c|c|c|c|c|}
\hline Liquid & $\begin{array}{c}\text { Density } \\
, \mathrm{kg} / \mathrm{m}^{3}\end{array}$ & $\begin{array}{c}\text { Kinemati } \\
\mathrm{C} \\
\text { viscosity, } \\
\mathrm{cSt}\end{array}$ & $\begin{array}{c}\text { Flash } \\
\text { point, } \\
{ }^{\circ} \mathrm{C}\end{array}$ & $\begin{array}{c}\text { Ignition } \\
\text { temperature } \\
{ }^{\circ} \mathrm{C}\end{array}$ & $\begin{array}{c}\text { Heat of } \\
\text { combustion, } \\
\mathrm{MJ} / \mathrm{kg}\end{array}$ & $\begin{array}{c}\text { Boiling } \\
\text { temperature } \\
{ }^{\circ} \mathrm{C}\end{array}$ & $\begin{array}{c}\text { Heat of } \\
\text { evaporation, } \\
\mathrm{MJ} / \mathrm{kg}\end{array}$ \\
\hline $\begin{array}{c}\text { Rapeseed } \\
\text { oil }\end{array}$ & 920 & 75 & 107 & 260 & 42.1 & 204 & 0.209 \\
\hline Diesel & 820 & 15 & $57-67$ & 300 & 42.4 & $240-347$ & 0.210 \\
\hline $\begin{array}{c}\text { Sunflower } \\
\text { oil }\end{array}$ & 865 & 60 & - & - & 37.5 & 225 & 0.21 \\
\hline Water & 997 & 14 & - & - & - & 100 & 2.26 \\
\hline
\end{tabular}




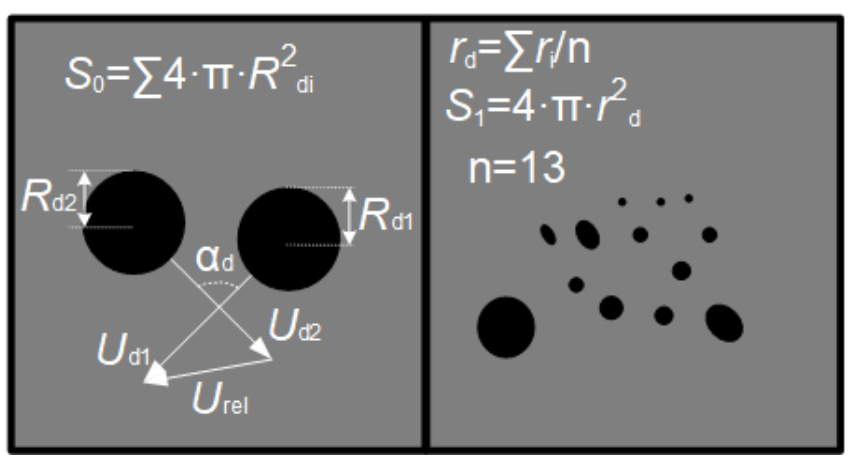

$a$

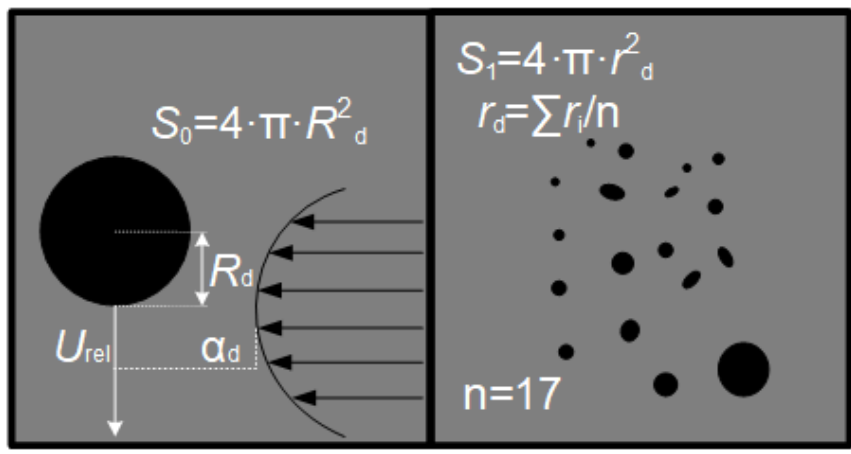

$C$

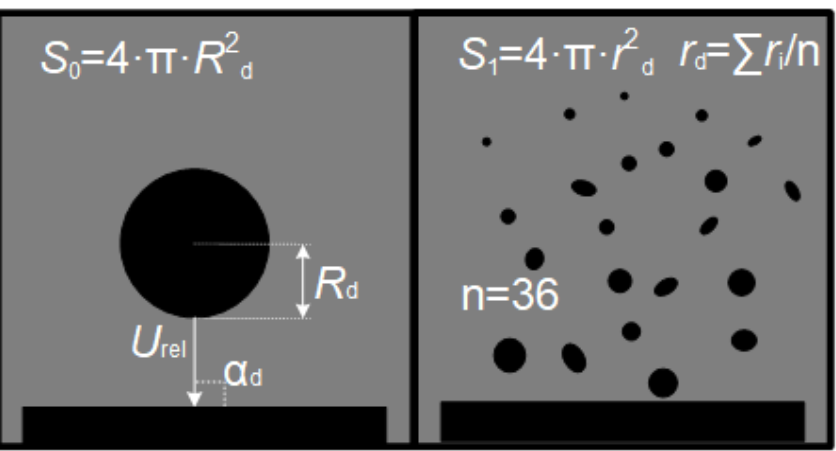

$b$

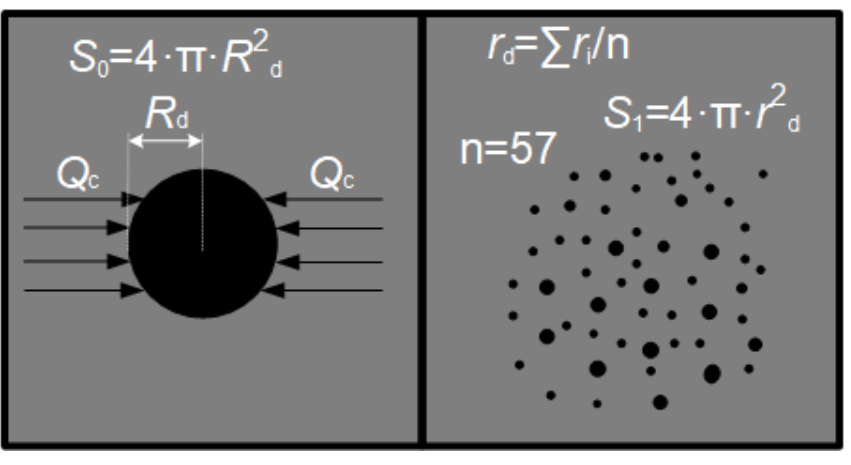

$d$

Fig. 1. Secondary droplet atomization schemes with key parameters: $a$-collisions; $b$ - wall impact; $c$ - air jet impact; $d$-micro-explosive breakup by overheating. 


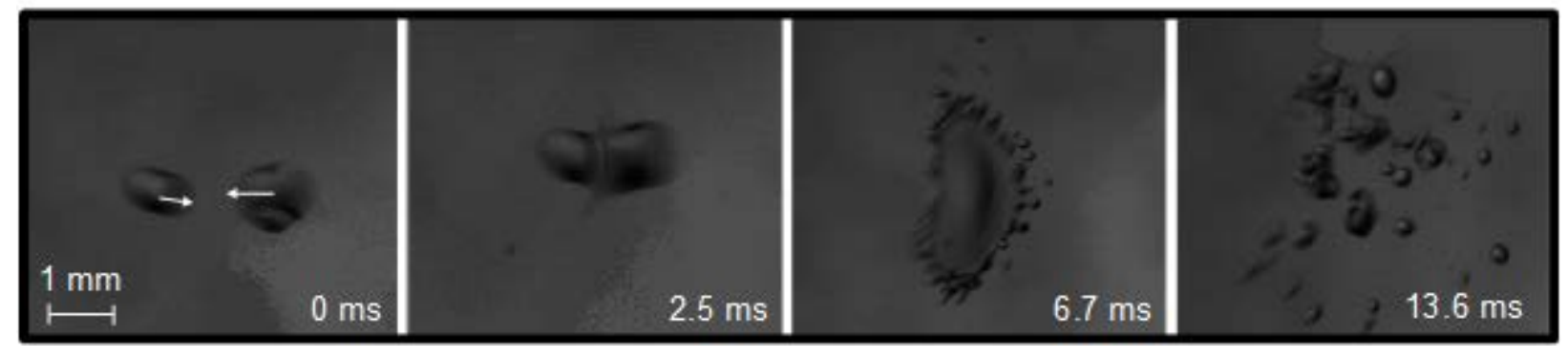

$a$

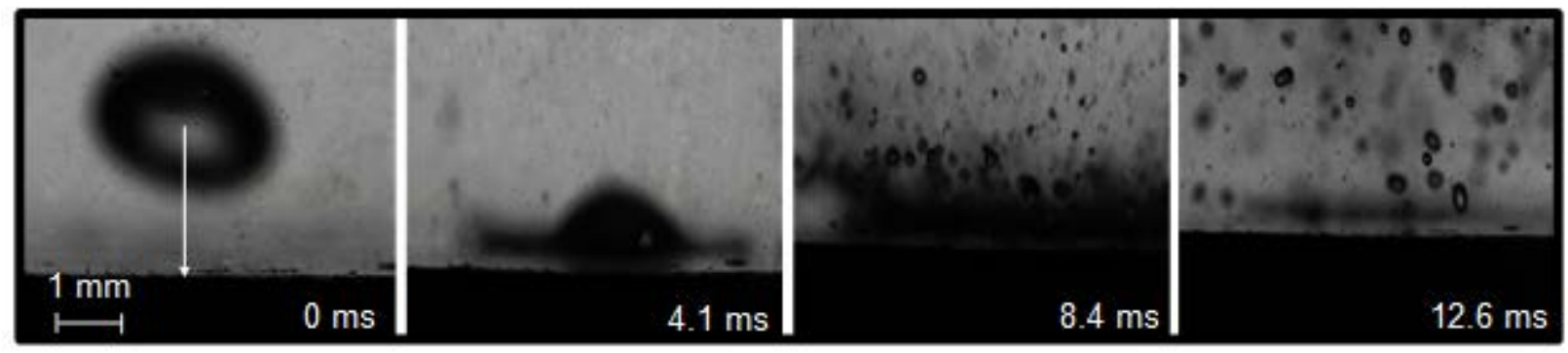

$b$

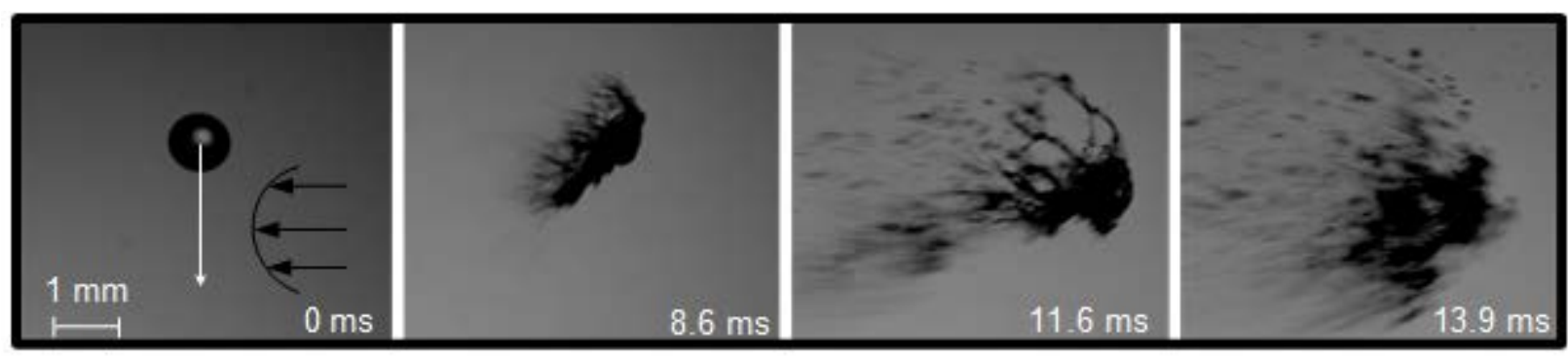

$C$

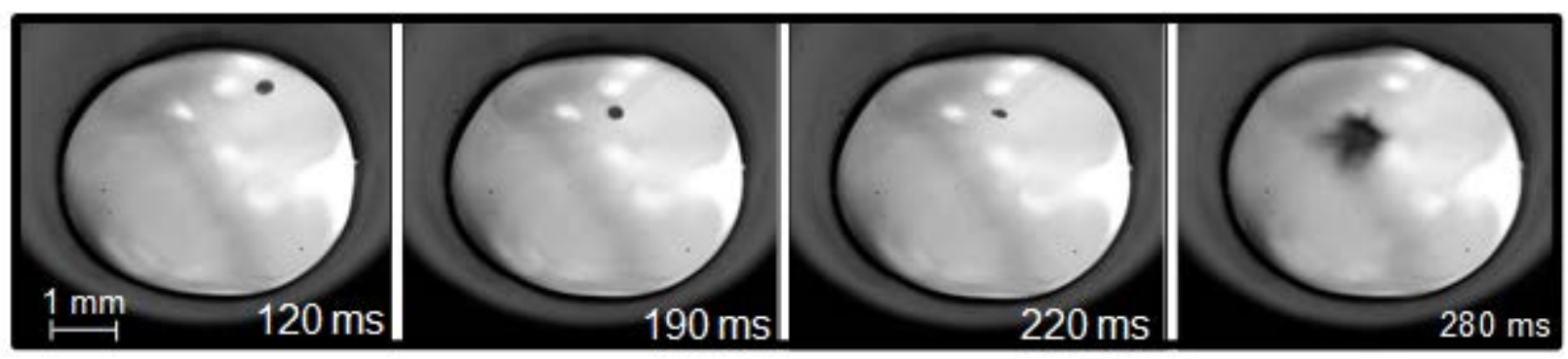

$d$

Fig. 2. Video frames of typical droplet (diesel fuel emulsion) disruption modes for four schemes: $a-$ collisions; $b$ - wall impact; $c$ - accelerated motion in the air flow; $d$ - micro-explosive breakup by convective heating. 

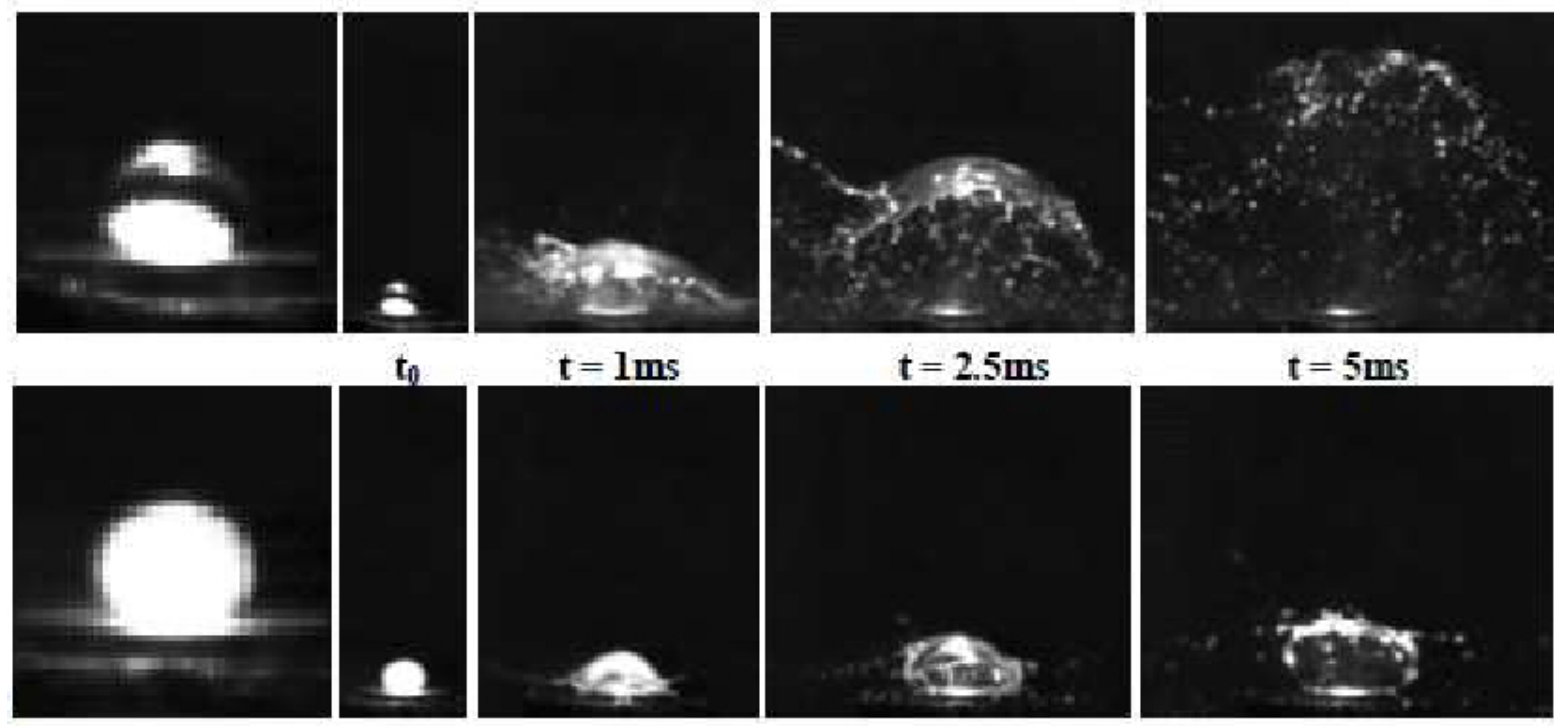

$\mathrm{t}=\mathrm{lms}$

$t=2.5 \mathrm{~ms}$

$t=5 \mathrm{~ms}$
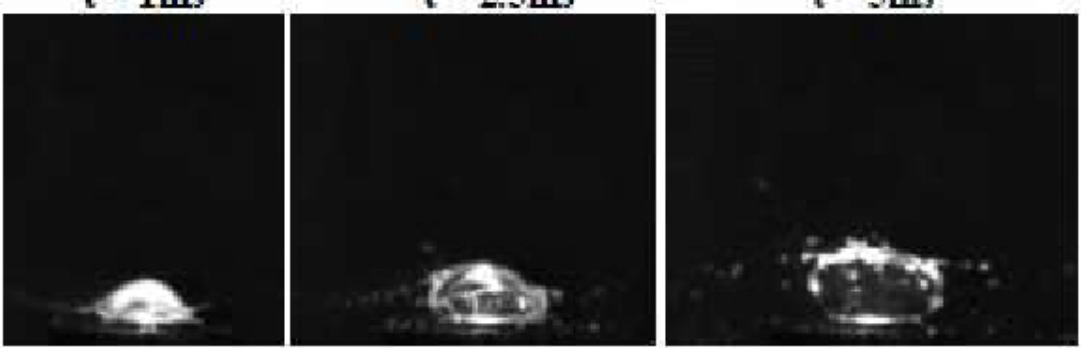

Fig. 3. Two video series of frames of the micro-explosion of a $2.5 \mathrm{~mm}$ water-in-oil emulsion drop, undergoing Leidenfrost effect onto a $363^{\circ} \mathrm{C}$ heated plate (reproduced from Mura et al. [17]). Microexplosion is optimal in the upper sequence of frames. 


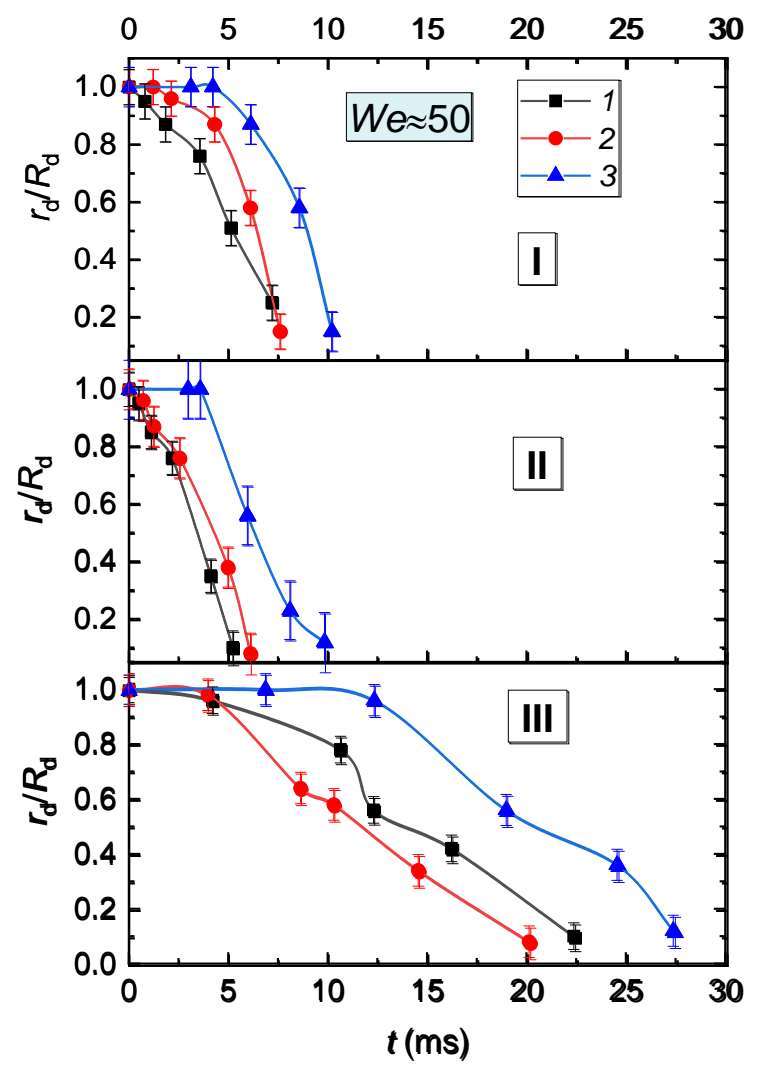

a

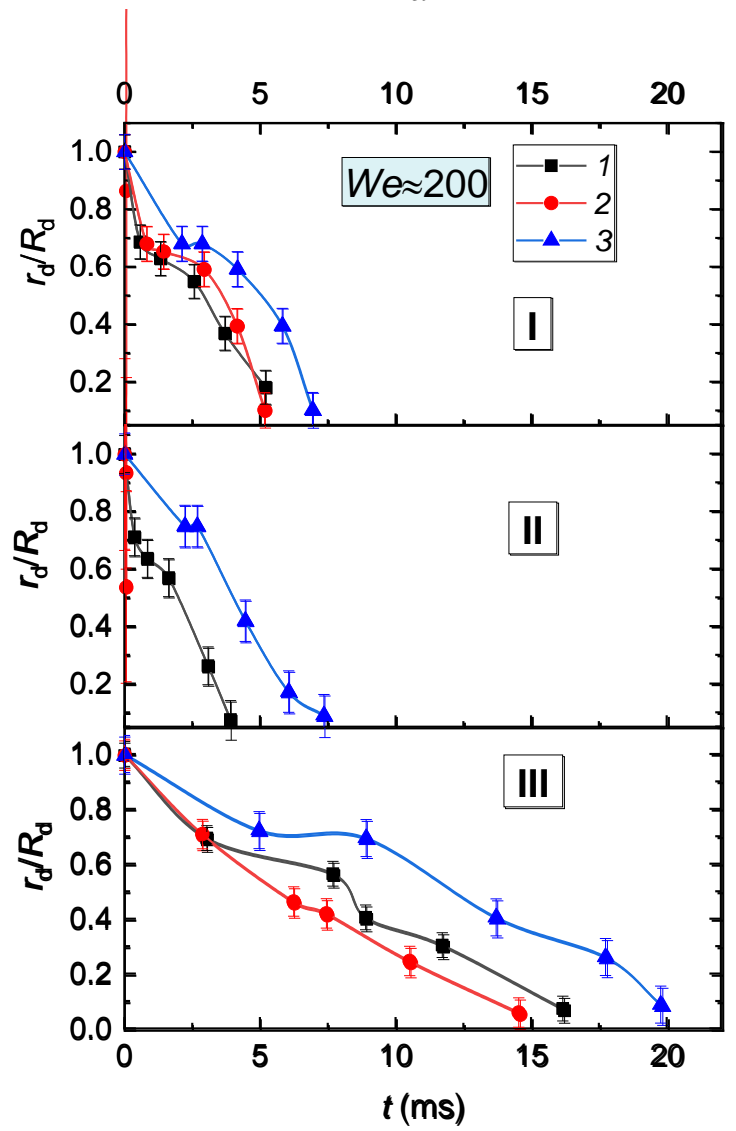

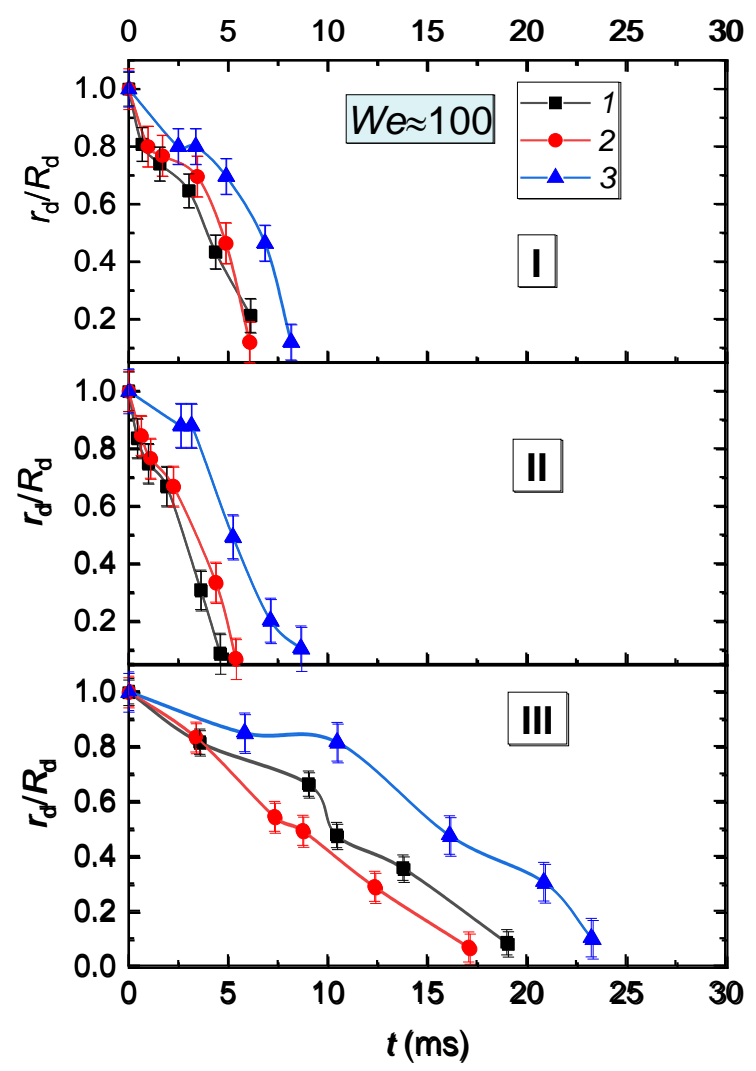

$b$

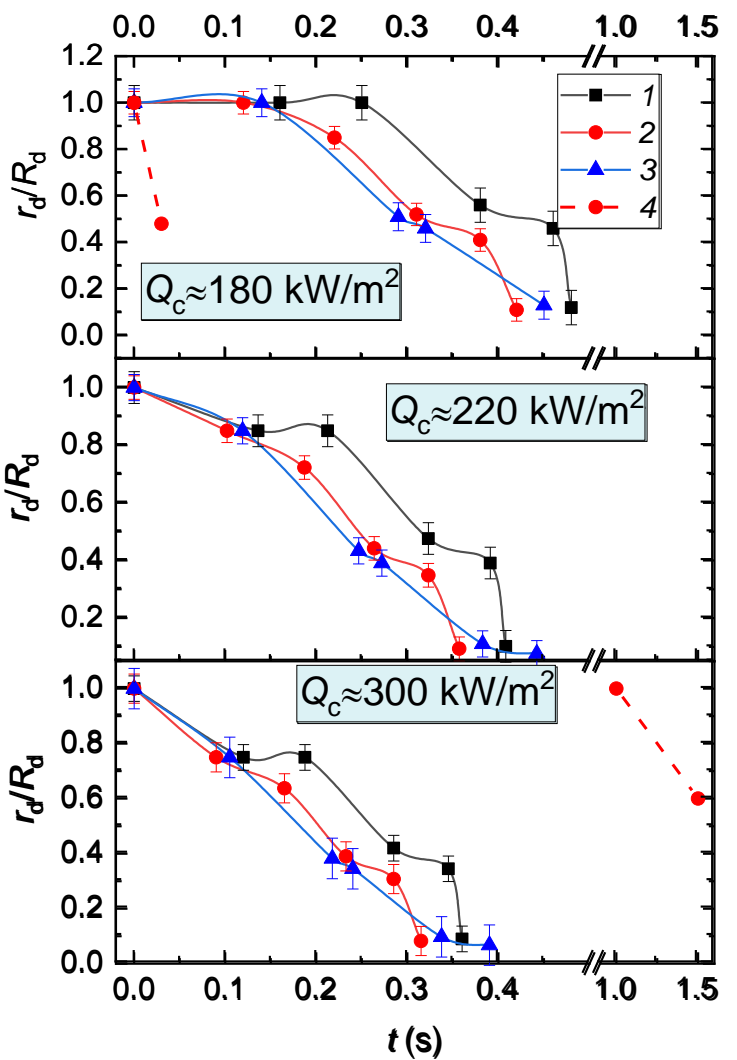

$d$

Fig. 4. Liquid fragment size variation for four secondary atomization approaches: $a, b, c$ - droplet secondary atomization at various Weber numbers (We $\approx 50,100,200$ ); I - collision of two droplets; II - droplet impact with the wall; III - droplet impact with the air jet; 1 - water; 2 - slurry; 3 - rapeseed oil emulsion; $d$ - 
micro-explosive droplet disruption (1 - rapeseed oil emulsion; 2 - diesel fuel emulsion; 3 - slurry; 4 experimental data from study [17] at $100 \mathrm{~kW} / \mathrm{m}^{2}$ and from study [18] at $375 \mathrm{~kW} / \mathrm{m}^{2}$ ).
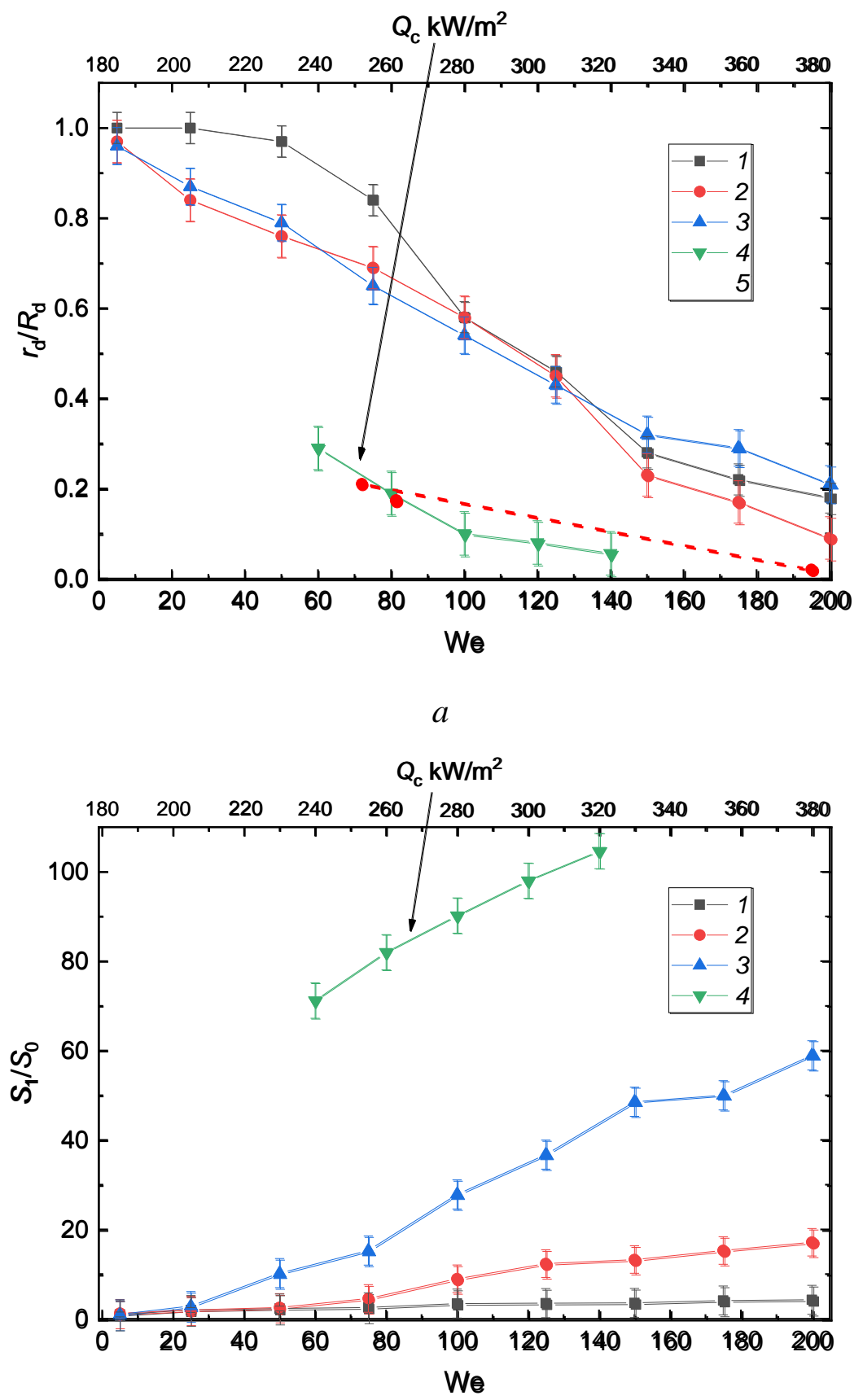

$b$

Fig. 5. Ratio of the average size $(a)$ and surface area $(b)$ of child-droplets to the initial value versus We number for rapeseed oil emulsion: 1 - collision of two droplets; 2 - droplet impact with the wall; 3 - droplet impact with the air jet; 4 - micro-explosive droplet disruption; 5 - experimental data from study [2]. 


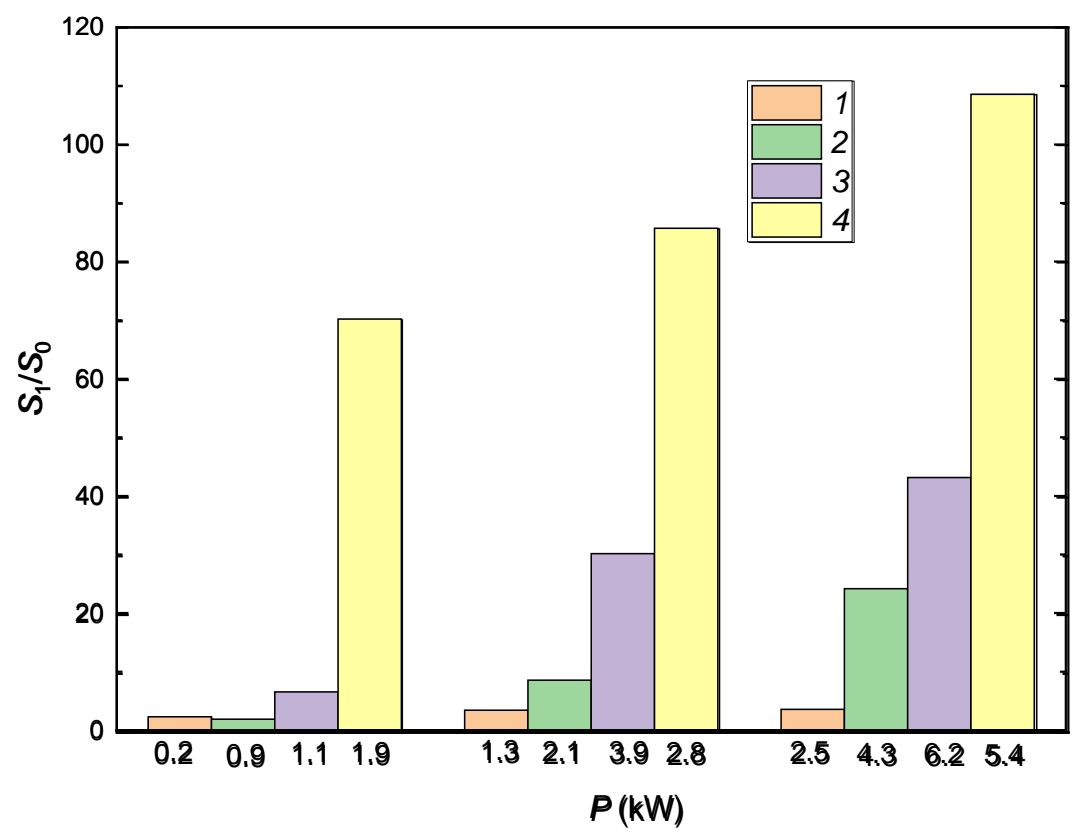

$a$

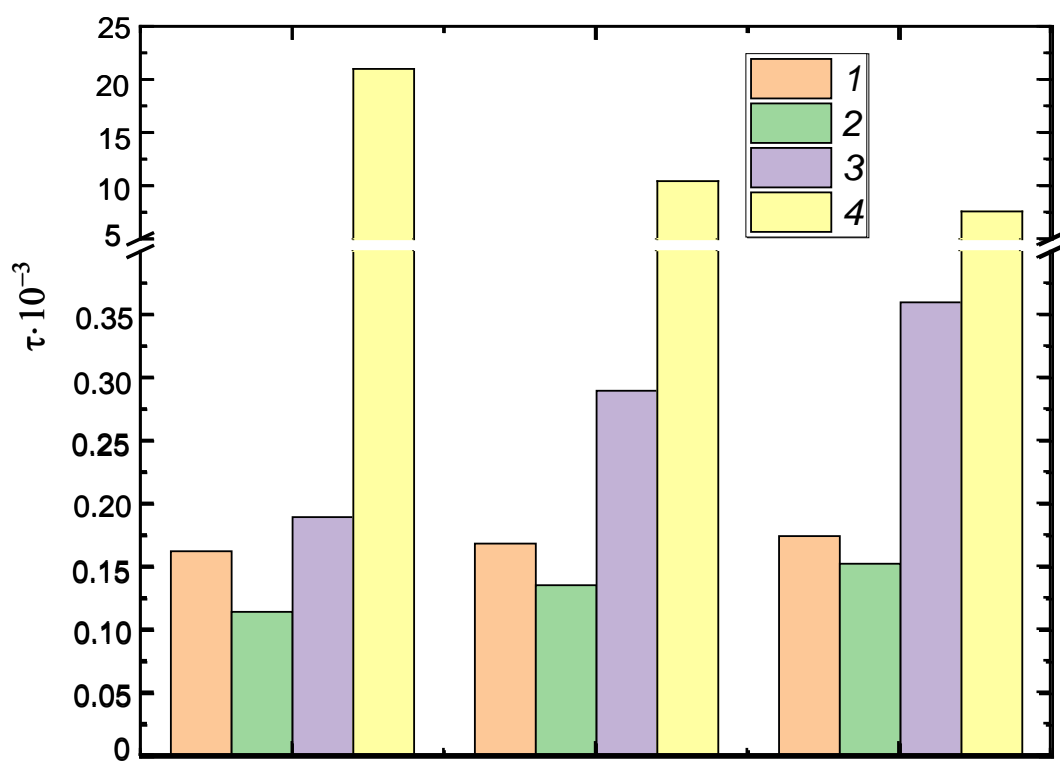

$b$

Fig. 6. Variation of the newly formed fragments' surface area to the initial value ratio $(a)$ with an increase in the consumed energy (for $\mathrm{We} \approx 50,100,150$, and for scheme 4, the heat flux values were 240, 280, 320 $\mathrm{kW} / \mathrm{m}^{2}$ ), as well as parent-droplet disruption time (for rapeseed oil emulsion) (b): 1 - droplet collision; 2 wall impact; 3 - air jet impact; 4 - micro-explosive breakup by overheating. 